\title{
Application of an Inter-Species Extrapolation Method for the Prediction of Drug Interactions between Propolis and Duloxetine in Humans
}

\author{
Thi Lien Ngo ${ }^{1}{ }^{\mathbb{D}}$, Chung-Hee Lee ${ }^{1}$, Nayoung Han ${ }^{2}$, Hyun-Moon Back ${ }^{3}$, Su-Jin Rhee ${ }^{4}{ }^{\mathbb{D}}$, \\ Keumhan Noh ${ }^{5}$, Hwi-Yeol Yun ${ }^{1}{ }^{1}$, Wonku Kang ${ }^{6, *}$ and Jung-Woo Chae ${ }^{1, *(1)}$ \\ 1 College of Pharmacy, Chungnam National University, Daejeon 34134, Korea; ngolienvp@gmail.com (T.L.N.); \\ choonghii@o.cnu.ac.kr (C.-H.L.); hyyun@cnu.ac.kr (H.-Y.Y.) \\ 2 College of Pharmacy, Seoul National University, Gwanak-ro 1, Gwanakgu, Seoul 08826, Korea; \\ hans1217@snu.ac.kr \\ 3 Department of Pharmaceutics, Ernest Mario School of Pharmacy, Rutgers, The State University of New \\ Jersey, Piscataway, NJ 08854, USA; hyunmoon.back@rutgers.edu \\ 4 Department of Clinical Pharmacology and Therapeutics, Seoul National University College of Medicine and \\ Hospital, Seoul 03080, Korea; rheesjin@snu.ac.kr \\ 5 Department of Pharmaceutical Sciences, Leslie Dan Faculty of Pharmacy, University of Toronto, \\ Toronto, ON M5S 3M2, Canada; keumhan.noh@utoronto.ca \\ 6 College of Pharmacy, Chung-Ang University, Seoul 06974, Korea \\ * Correspondence: wkang@cau.ac.kr (W.K.); jwchae@cnu.ac.kr (J.-W.C.); Tel.:+82-2-816-5601 (W.K.); \\ +82-42-821-5929 (J.-W.C.); Fax: 82-2-816-7338 (W.K.); 82-42-822-5343 (J.-W.C.)
}

Received: 4 December 2019; Accepted: 5 March 2020; Published: 9 March 2020

\begin{abstract}
Duloxetine (DLX) is a potent drug investigated for the treatment of depression and urinary incontinence. DLX is extensively metabolized in the liver by two P450 isozymes, CYP2D6 and CYP1A2. Propolis (PPL) is one of the popular functional foods known to have effects on activities of CYPs, including CYP1A2. Due to the high probability of using DLX and PPL simultaneously, the present study was designed to investigate the potent effect of PPL on pharmacokinetics (PKs) of DLX after co-administration in humans. A PK study was first conducted in 18 rats ( $n=6 /$ group), in which the plasma concentration of DLX and its major metabolite 4-hydroxy duloxetine (4-HD) with or without administration of PPL was recorded. Population PKs and potential effects of PPL were then analyzed using NONMEM software. Lastly, these results were extrapolated from rats to humans using the allometric scaling and the liver blood flow method. PPL (15,000 mg/day) exerts a statistically significant increase in DLX exposures at steady state, with a $20.2 \%$ and $24.6 \%$ increase in DLX $C_{\max , s s}$ and the same $28.0 \%$ increase in DLX $A U C_{s s}$ when DLX (40 or $60 \mathrm{mg}$ ) was administered once or twice daily, respectively. In conclusion, safety issues are required to be attended to when individuals simultaneously use DLX and PPL at high doses, and the possibility of interactions between DLX and PPL might be noted.
\end{abstract}

Keywords: duloxetine; propolis; drug interaction; extrapolation; CYP1A2

\section{Introduction}

Propolis (PPL) is a resin-like material made by honeybees from the buds of poplar and cone-bearing trees and is used in beehive construction and maintenance. PPL has been used in traditional medicine for centuries worldwide [1,2]. A significant body of evidence has shown that extracts of PPL have anti-inflammatory [3], anticancer [4,5], antioxidant [6], antifungal [7], antibacterial [8], and antivirus [9] activities. These biological activities depend mainly upon the chemical composition of the constituents, 
which vary considerably depending on the type of plants accessible to the bees as well as the sites of collection. Currently, PPL is widely used as popular functional foods and beverages that found in many health food stores for treating various diseases. One of the most common applications of PPL is to support the immune system for treatment of cold syndromes, including upper respiratory tract infections, the common cold, and flu-like infections. Since PPL is considered to be a health supplement, not a drug, PPL dosage is generally recommended by manufacturers on the product label without any guideline from heath organizations.

Previous literature has reported that PPL has protective effects against chemical-induced liver injury [10-12]. For example, PPL pretreatment protected against acetaminophen-induced hepatotoxicity in mice. One of the protective mechanisms was that PPL inhibited the formation of $N$-acetyl-p-benzoquinoneimine (an active metabolite of acetaminophen), which was produced by cytochrome P450 (CYP) enzymes [10]. Changes in the activity of CYP450 enzymes is one of the reasons for interactions between supplements and drugs that may cause adverse events. Therefore, effects of PPL and its major ingredients on CYP450 activities has been characterized recently [13-16]. For instance, Naramoto et al. has reported that ethanol extraction of Brazilian Green PPL inhibited enzymatic activities of all the tested CYP enzymes (CYP1A2, 2C9, 2C19, 2D6, and 3A4) in vitro in a concentration-dependent manner [13]. The inhibition effects of PPL on CYP1A2, 2E1, and 2C19 activities in vitro and in vivo have also been reported in our recently study [14]. Interestingly, none of published studies had evaluated the interactions of PPL with clinical drugs in humans, although PPL has been used widely as a health supplement.

Duloxetine (DLX), (+)-(S)-N-methyl- $\gamma$-(1-naphthyloxy)-2-thiophenrpropylamine, administered as duloxetine hydrochloride, is a potent and selective serotonin and norepinephrine reuptake inhibitor. This drug is used clinically in many countries for the treatment of disorders related to norepinephrine and serotonin, including major depressive disorder, diabetic peripheral neuropathic pain, and generalized anxiety disorder $[17,18]$. The drug is rapidly and extensively metabolized by CYP1A2, and to a lesser degree, by CYP2D6, to form multiple oxidative metabolites, which are then conjugated before being excreted in the urine [19]. Correspondingly, the glucuronide conjugate of 4-hydroxy duloxetine (4-HD) and the sulfate conjugate of 5-hydroxy-6-methoxy duloxetine are the two major metabolites of DLX in plasma [19]. A clinical study by Lobo et al. [20] reported that following a single oral DLX dose, the co-administration of fluvoxamine (a strong CYP1A2 inhibitor) resulted in clinically important increases in the DLX $A U C_{0-\infty}(460 \%)$ and $C_{\max }(141 \%)$. To explain these significant increases, the authors suggested that fluvoxamine increased the amount of DLX absorbed into systemic circulation by decreasing the extent of first-pass metabolism and, additionally, decreased systemic clearance of DLX by inhibiting CYP1A2-mediated metabolism.

Since only DLX has pharmacological effects, while all its circulating metabolites are inactive, any interaction resulting in a variation in DLX metabolism may alter its therapeutic effects, safety, and/or adverse events [17]. Nowadays, many people, especially elderly people, usually take drugs and supplementary simultaneously. As PPL is widely used for addressing various diseases, there is a high probability that DLX and PPL are administered at the same time. This study was conducted to investigate potential effects of PPL on the pharmacokinetic (PK) profile of DLX when they are co-administered in humans, using population PK model-based approach [21,22]. First, a PK study for drug interactions between DLX and PPL was conducted in rats. A population PK model was subsequently developed using nonlinear mixed-effects modelling (NONMEM) software to describe the PK profiles of DLX and its major metabolite 4-HD in rats. The results were then extrapolated from rats to humans by applying the simple allometric scaling method [23-26] and the liver blood flow (LBF) method $[27,28]$. 


\section{Results}

\subsection{PK Data of DLX and 4-HD in Rats}

Plasma concentration of DLX and 4-HD after a single oral dose of $40 \mathrm{mg} / \mathrm{kg}$ DLX or a single oral dose of $40 \mathrm{mg} / \mathrm{kg}$ DLX with 500 or $1500 \mathrm{mg} / \mathrm{kg}$ PPL in rats were determined using a high-performance liquid chromatography-tandem mass spectrometer (HPLC-MS/MS) method. The calibration curves established by plotting the peak area ratio vs. concentration were linear in the range of 5-1000 ng/mL for both of these two analytes $\left(R^{2}>0.99\right)$. During the method validation, all the test results met the required criteria according to the U.S Food and Drug Administration (FDA) guidelines for bioanalytical method validation [29]. Individual and mean of population of plasma concentration-time curves of DLX and 4-HD are illustrated in Supplementary Materials Figure S1.

\subsection{Population PK Model for DLX and 4-HD in Rats}

The final population PK model used to describe the PKs of DLX and its metabolite 4-HD with characterizing the metabolism of DLX converted to 4-HD was chosen after testing various models based on the objective function value (OFV) changes and goodness of fit (GOF) plots. A summary of building steps for covariate models resulting in statistical significance in the OFV during the model development is listed in Table 1. As demonstrated, PPL showed a significant inhibitory effect $(p<0.000)$ on the fraction of 4-HD converted from DLX $\left(F_{p m}\right)$ at the depot, as well as the conversion of DLX to 4-HD $\left(C L_{p m}\right)$ at the systemic circulation.

Table 1. Summary of covariate model building steps.

\begin{tabular}{cccccc}
\hline Model No. & Model Description & df. & $\begin{array}{c}\text { Change in } \\
\text { OFV }\end{array}$ & $\begin{array}{c}\text { Compared } \\
\text { with }\end{array}$ & $\begin{array}{c}\text { Significance } \\
(p \text {-Value })\end{array}$ \\
\hline 1 & Base model & - & - & - & - \\
\hline 2 & $\begin{array}{c}\text { Model 1 with PPL as } \\
\text { covariate for Fpm }\end{array}$ & 1 & -38.4 & Model 1 & $<0.000$ \\
\hline 3 & $\begin{array}{c}\text { Model 1 with PPL as } \\
\text { covariate for CLpm }\end{array}$ & 2 & -28.7 & Model 1 & $<0.000$ \\
\hline $4^{\text {a }}$ & $\begin{array}{c}\text { Model 1 with PPL as } \\
\text { covariate for Fpm and CLp }\end{array}$ & 3 & -47.8 & Model 1 & $<0.000$ \\
\hline $4^{\text {a }}$ & $\begin{array}{c}\text { Model 1 with PPL as } \\
\text { covariate for Fpm and CLp }\end{array}$ & 2 & -10.6 & Model 2 & $<0.005$ \\
\hline
\end{tabular}

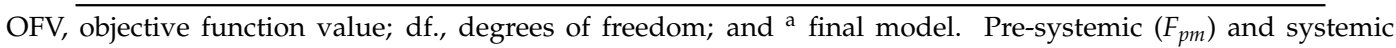
$\left(C L_{p m}\right)$ metabolisms.

$\left(F_{p m}\right)$ and systemic $\left(C L_{p m}\right)$ metabolisms.

PKs of DLX and 4-HD were well described by a one-compartment disposition model, with first-order elimination and first-order absorption kinetics. The metabolism of DLX converted to 4-HD was described by two metabolism pathways, including the first-pass effect and the systemic metabolism (Figure 1). The covariate effects of PPL on PK of DLX were modeled using a Michaelis Menten equation, as described in the following equations (Equations (1) and (2)) and illustrated in Figure 2.

$$
\begin{gathered}
\text { CLpm }=1.26 \times\left(1-1 \times \frac{\operatorname{Dose}_{P P L}}{\operatorname{Dose}_{P P L}+276}\right) \\
F p m=0.589 \times\left(1-0.147 \times \frac{\operatorname{Dose}_{P P L}}{\text { Dose }_{P P L}+538}\right)
\end{gathered}
$$




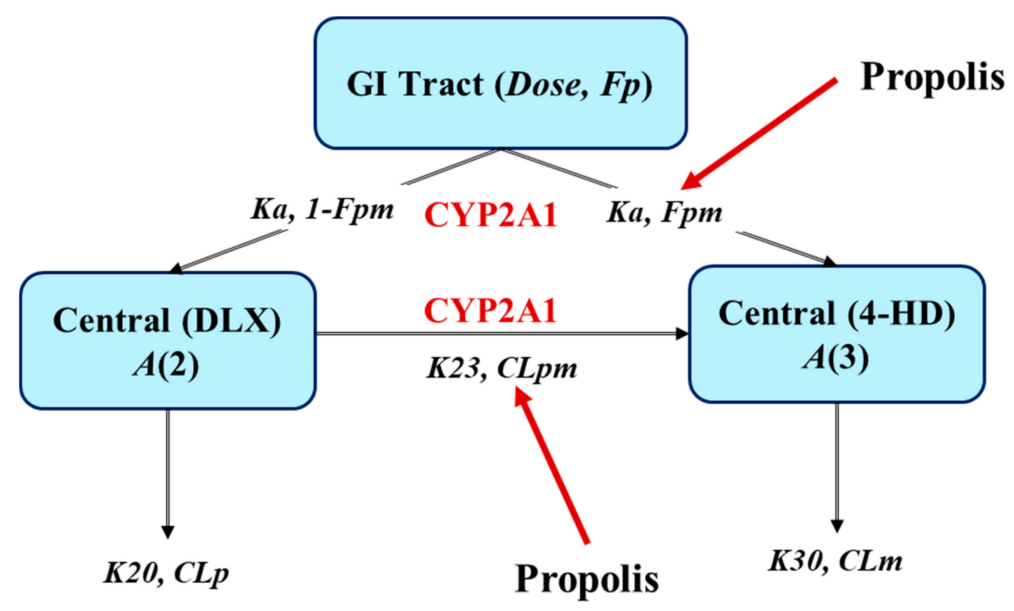

Figure 1. Schematic representation of the base population pharmacokinetic (PK) model for DLX and its metabolite, 4-HD, and strategies to investigate the effect of PPL on the PKs of DLX after a single oral dose of $40 \mathrm{mg} / \mathrm{kg}$ DLX in rats. Notations are described in the main text. Pre-systemic $\left(F_{p m}\right)$ and systemic $\left(C L_{p m}\right)$ metabolisms.

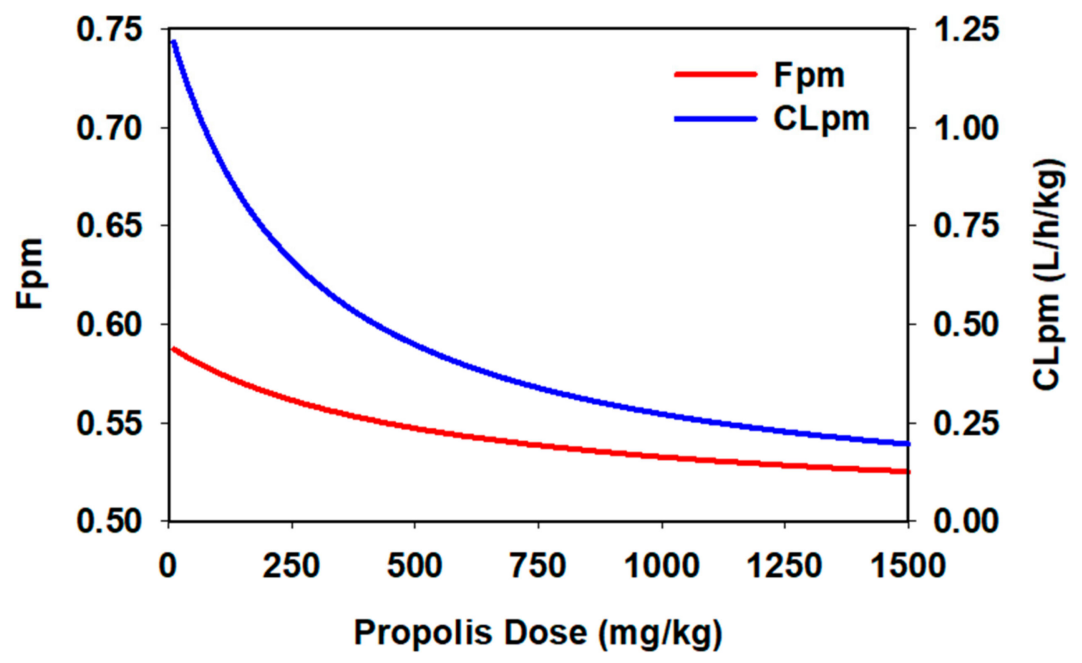

Figure 2. Predicted conversion fractions of DLX to 4-HD via the pre-systemic $\left(F_{p m}\right)$ and systemic $\left(C L_{p m}\right)$ metabolisms according to the different administered doses of PPL.

By using the final model, only clearance of DLX via all elimination routes except the conversion to $4-\mathrm{HD}$ via the systemic metabolism from the body $\left(C L_{p}\right)$ need to be modeled with inter-individual variation effect. Estimates of fixed effects, intra- and inter-individual random effects, and their relative standard errors (\% RSE) for the estimations are listed in Table 1. As shown in Table 2, the PK parameters of DLX and 4-HD in rats were generally well-estimated, with their \% RSE in the range of $8.10 \%-85.7 \%$, except IC50_F $F_{p m}(358 \%)$. The IIV estimate for $C L_{p}$ was $7.9 \%$ with an RSE of $70 \%$. Accordingly, a decrease by $149 \%$ (from $149 \%$ to $0 \%$ ) in IIV of $C L_{p m}$ and a decrease by $10.5 \%$ (from $18.4 \%$ to $7.9 \%$ ) in IIV of $C L_{p}$ were observed in comparison to the base model. The proportional residual error was $19.9 \%$ (for DLX) and 24.0\% (for 4-HD). 
Table 2. Parameter estimates from the final model and results of bootstrap validation for DLX and 4-HD after a single oral administration of DLX at dose of $40 \mathrm{mg}$ without or with co-administration with PPL 500 or $1500 \mathrm{mg} / \mathrm{kg}$ in rats.

\begin{tabular}{|c|c|c|c|c|c|c|c|c|}
\hline \multirow{2}{*}{ Parameters } & \multirow{2}{*}{ Unit } & \multirow{2}{*}{ Estimates } & \multirow{2}{*}{ RSE (\%) } & \multirow{2}{*}{ Shrinkage (\%) } & \multicolumn{4}{|c|}{ Bootstrap Replicates $(n=1000)$} \\
\hline & & & & & Median & & $95 \%$ & \\
\hline$K_{a}$ & $1 / \mathrm{h}$ & 1.35 & 8.10 & & 1.35 & 1.24 & - & 1.45 \\
\hline Emax_F $F_{p m}$ & & 0.147 & 85.7 & & 0.198 & 0.0435 & - & 0.844 \\
\hline IC50_F $F_{p m}$ & $\mathrm{mg} / \mathrm{kg}$ & 538 & 358 & & 806 & 45.7 & - & 5478 \\
\hline$F_{p m}$ & & 0.589 & 15.9 & & 0.574 & 0.451 & - & 0.746 \\
\hline$C L_{p}$ & $\mathrm{~L} / \mathrm{h} / \mathrm{kg}$ & 1.97 & 22.6 & & 2.10 & 1.08 & - & 2.80 \\
\hline$V_{p}^{r}$ & $\mathrm{~L} / \mathrm{kg}$ & 14.6 & 26.4 & & 15.1 & 9.01 & - & 19.6 \\
\hline Emax_CL $L_{p m}$ & & 1.00 & & & 1.00 & 1.00 & - & 1.00 \\
\hline IC50_C $L_{p m}$ & $\mathrm{mg} / \mathrm{kg}$ & 276 & 77.2 & & 270 & 60.1 & - & 596 \\
\hline$C L_{p m} / F_{p}$ & $\mathrm{~L} / \mathrm{h} / \mathrm{kg}$ & 1.26 & 30.7 & & 1.24 & 0.770 & - & 1.77 \\
\hline$C L_{m} / F_{m}$ & $\mathrm{~L} / \mathrm{h} / \mathrm{kg}$ & 12.3 & 13.6 & & 11.9 & 9.45 & - & 16.0 \\
\hline$V_{m} / F_{m}$ & $\mathrm{~L} / \mathrm{kg}$ & 84.2 & 21.6 & & 81.3 & 64.3 & - & 110 \\
\hline \multicolumn{9}{|c|}{ Inter-individual variability (IIV, \%) } \\
\hline $\mathrm{IIV} C L_{p}$ & & 7.90 & 70.0 & 14.0 & 7.10 & 3.21 & - & 10.2 \\
\hline \multicolumn{9}{|c|}{ Residual variability (\%) } \\
\hline Prop_p & & 19.9 & 13.4 & & 19.8 & 18.0 & - & 21.9 \\
\hline Prop_m & & 24.0 & 10.3 & & 23.5 & 20.8 & - & 26.2 \\
\hline
\end{tabular}

RSE, relative standard error; IIV, inter-individual variation; CI, confidence interval (the $2.5^{\text {th }}$ and $97.5^{\text {th }}$ percentiles); Prop_p and Prop_ $m$ are the proportional residual errors for DLX and 4-HD, respectively; $F_{p m}$, conversion fractions of DLX to 4-HD via the pre-systemic metabolism; $C L_{p m}$, clearance of DLX via the conversion to 4-HD via the systemic metabolism; $C L_{p}$, clearance of DLX via all elimination routes except the conversion to 4-HD via the systemic metabolism; $K_{a}, V_{p}$, and $F_{p}$ : absorption rate constant, volume of distribution, and bioavailability of DLX after the pre-systemic metabolism, respectively; and $C L_{m}, V_{m}$, and $F_{m}$ : clearance, volume of distribution, and bioavailability of 4-HD, respectively.

The basic GOF plots of the final model of the plasma concentration-time profiles of DLX and 4-HD are shown in Figure 3, suggesting that the individual prediction concentrations were reasonably well fitted by the final covariate model. The population and individual post-hoc predictions were distributed around the line of identity with no systematic bias. Moreover, conditional weighted residuals for the population predicted plasma concentrations were generally distributed around zero and were symmetric.

\subsection{Population PK Model Evaluation}

Evaluation and selection of the models were based on graphical analysis (visual predictive check, VPC plots) as well as statistical methods (bootstrap analysis). The predicted concentrations from 1000 simulated datasets using the final model for DLX and 4-HD after a single oral dose of $40 \mathrm{mg}$ DLX and a variable dose of PPL in rats are shown in Figure 4. As illustrated in Figure 4, all of the observed concentrations were within the $5^{\text {th }}-95^{\text {th }}$ percentiles of the simulated concentrations. In addition, the majority of the observed median values were within the $95 \%$ confidence interval of the predicted median values obtained by the simulation. Results of the bootstrap analysis are listed in Table 2, indicating the parameter estimates of the final model were in the $2.5^{\text {th }}-97.5^{\text {th }}$ percentiles and were close to the medians estimated from bootstrap replicates. This result demonstrated that the parameter estimates of the final model were not statistically different from the parameters estimated by the bootstrap process. 

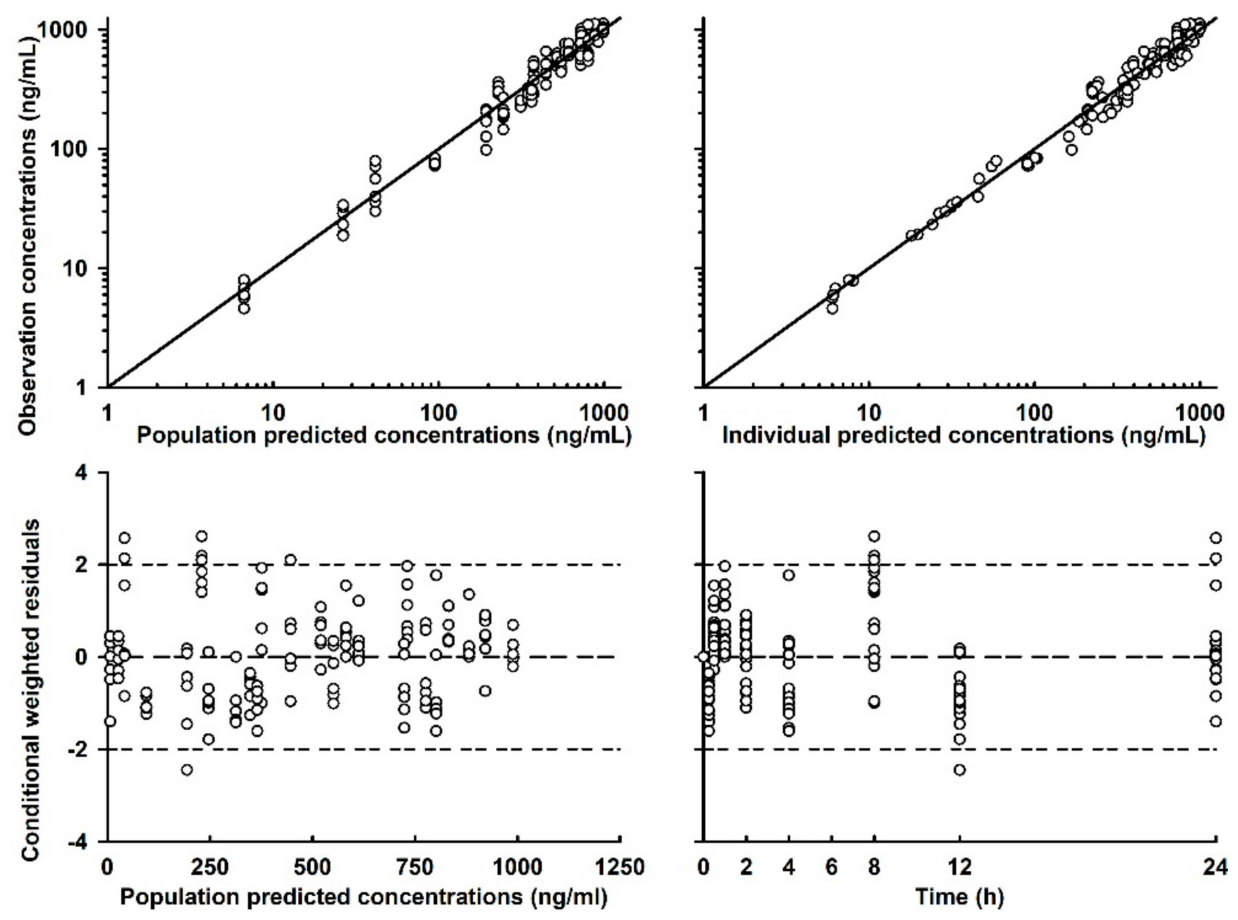

(A)
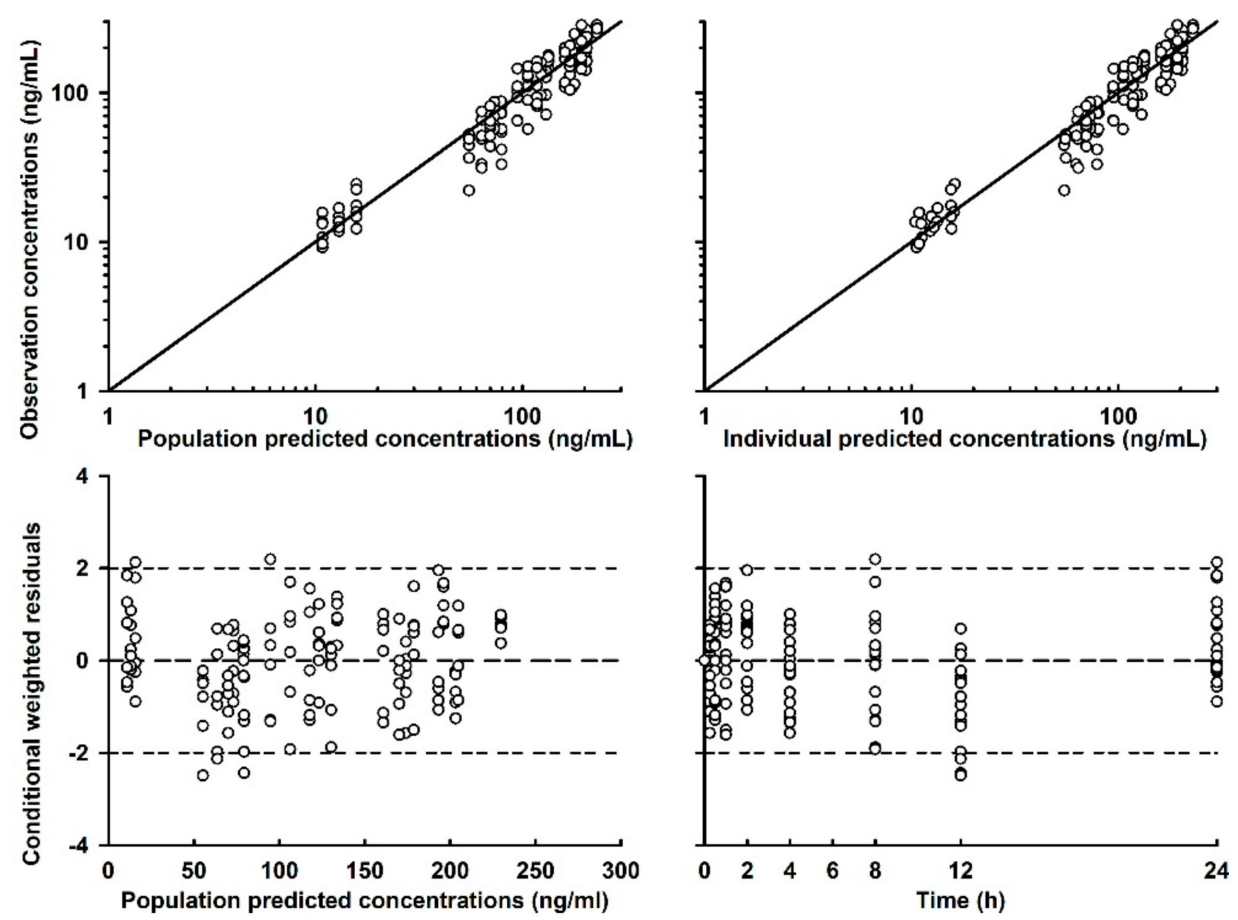

(B)

Figure 3. Goodness of fit plots for the final model for predictions of the PK profiles of (A) DLX and (B) 4-HD in rats. 

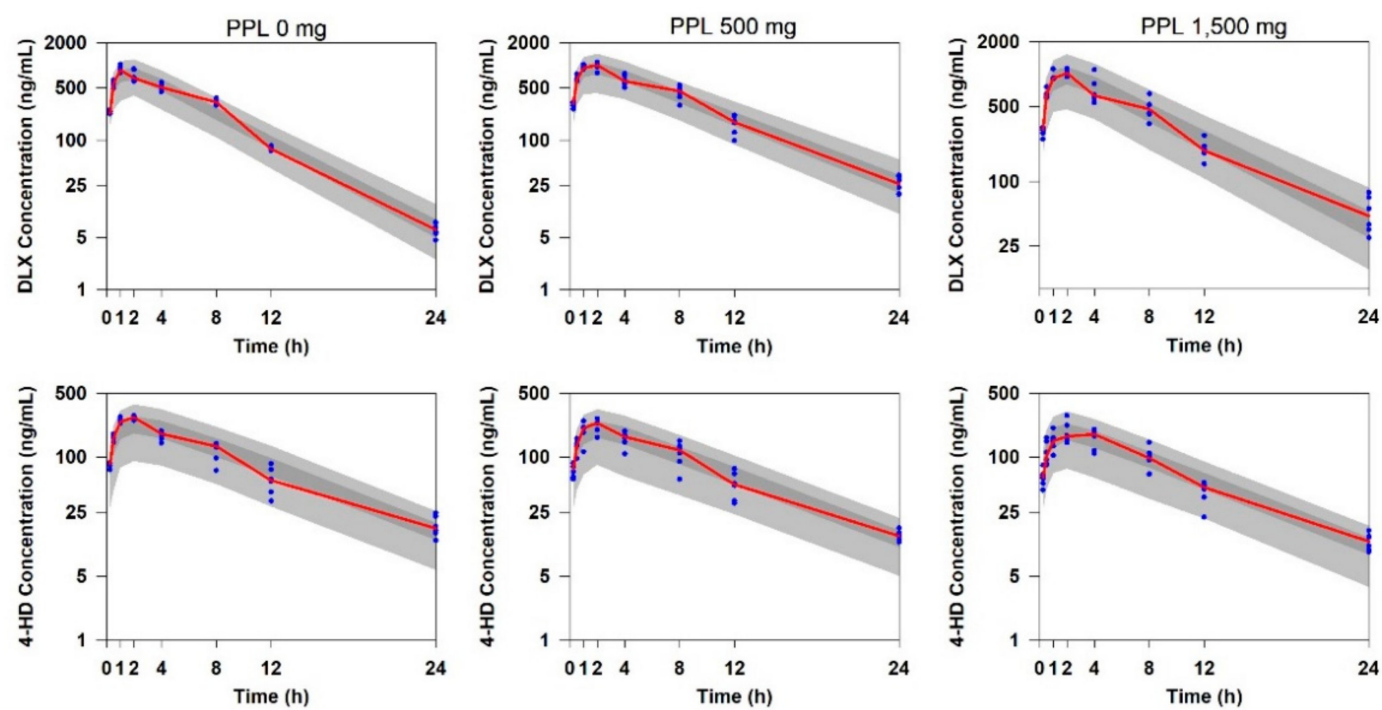

Figure 4. Visual predictive check plots for the final model for predictions of the PK profiles of (upper) DLX and (lower) 4-HD in rats. Open circles: observed concentrations, solid red line: median of the observed concentrations, dark grey area: $95 \%$ confidence interval $\left(2.5^{\text {th }}-97.5^{\text {th }}\right.$ percentiles $)$ of the median predicted concentrations, and light grey area: $90 \%$ prediction intervals $\left(5.0^{\text {th }}\right.$ to $95.0^{\text {th }}$ percentiles) of the predicted concentrations.

\subsection{Extrapolation of PKs of DLX and 4-HD in Humans}

PK parameters of DLX and 4-HD in humans extrapolated from rats and from previous studies, including absorption rate constant $K_{a}$, elimination rate constant $K_{e}$, apparent oral clearance $\left(C L_{p m} / F_{p}\right.$ and $\left.C L_{p} / F_{p}\right)$, volume of distribution $\left(V_{p} / F_{p}\right)$ of DLX, where $F_{p}$ is bioavailability of DLX after the first-pass effect, and apparent clearance $C L_{m} / F_{m}$ and apparent volume of distribution $V_{m} / F_{m}$ of 4-HD, where $F_{m}$ is bioavailability of 4-HD, are listed in Table 3. Other PK parameters, including the effects of PPL dose on the PKs of DLX, as well as the IIV and RSE of all PK parameters in humans, were assumed to be the same as in the rats. The predicted total clearance $\left(C L_{D L X} / F_{p}\right)$ and volume of distribution $\left(V_{p} / F_{p}\right)$ of DLX was $55.9 \mathrm{~L} / \mathrm{h}$ and $1022 \mathrm{~L}$, respectively. Following conversion, the predicted apparent total clearance $\left(C L_{D L X} / F_{D L X}\right)$ and volume of distribution $\left(V_{D L X} / F_{D L X}\right)$ was $136 \mathrm{~L} / \mathrm{h}$ and 2487 $\mathrm{L}$, respectively, where $F_{D L X}$ is the total bioavailability of DLX. In other words, the fraction of drug that reaches the systemic circulation from the DLX dose is calculated following the Equation (3) below:

$$
F_{D L X}=\left(1-F_{p m}\right) \times F_{p}
$$

Table 3. Predicted PK parameters of DLX and 4-HD in humans extrapolated from rats and experimental human parameters in literatures.

\begin{tabular}{ccc}
\hline Parameters & Unit & Predicted Value \\
\hline$K_{a}$ & $1 / \mathrm{h}$ & 0.687 \\
$C L_{p} / F_{p}$ & $\mathrm{~L} / \mathrm{h}$ & 34.1 \\
$C L_{p m} / F_{p}$ & $\mathrm{~L} / \mathrm{h}$ & 21.8 \\
$V_{p} / F_{p}$ & $\mathrm{~L}$ & 1022 \\
$K_{e p}$ & $1 / \mathrm{h}$ & 0.0547 \\
$C L_{m} / F_{m}$ & $\mathrm{~L} / \mathrm{h}$ & 212 \\
$C L_{m} / F_{m}$ & $\mathrm{~L} / \mathrm{h}$ & 5894
\end{tabular}

An average of human body weight of $70 \mathrm{~kg}$ was assumed. $K_{a}$ was predicted based on the relationship between $K_{a}$, $K_{e}$, and $T_{\max }$ as: $T_{\max }=\frac{\ln K a-\ln K e}{K a-K e}$, where $T_{\max }=4 \mathrm{~h}$ and $K_{e}=\frac{C L p m+C L p}{V p}$. 
The predicted PK profile of DLX and 4-HD following a single oral administration of DLX at the dose of 40 or $60 \mathrm{mg}$ in humans is illustrated in Figure 5. The maximum concentration $\left(C_{\max }\right)$ and area under the concentration-time curves $(A U C)$ from zero to last time $\left(A U C_{0-t}\right)$ of DLX are listed in Table 4.

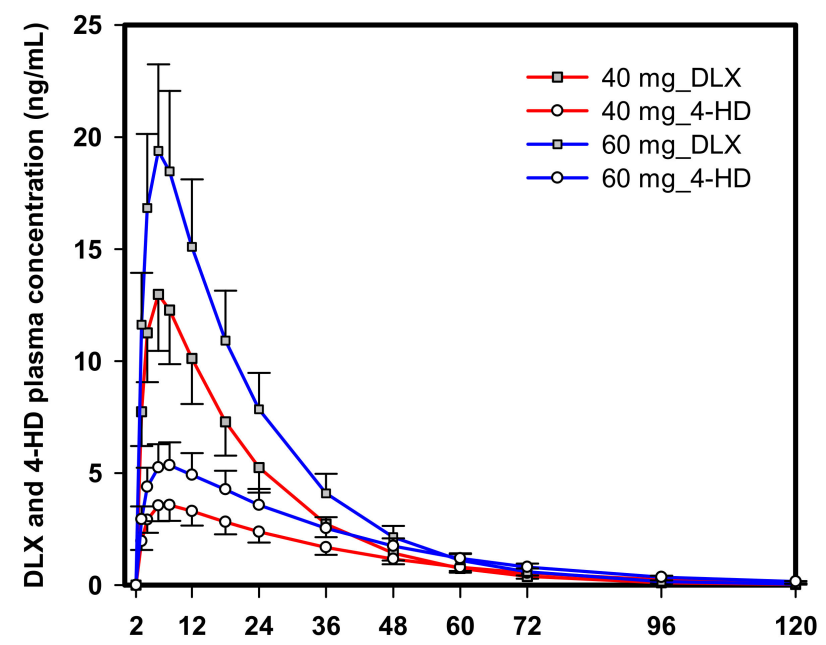

Figure 5. Extrapolated concentration-time curve profiles of DLX and 4-HD after a single oral administration of $40 \mathrm{mg}$ or $60 \mathrm{mg}$ in humans. Data are presented as means (solid square, DLX and open circles, 4-DH) and standard deviations (error bars).

Table 4. Pharmacokinetic (PK) parameters of DLX in humans according to different co-administered doses of PPL.

\begin{tabular}{|c|c|c|c|c|c|c|c|}
\hline \multicolumn{2}{|c|}{ Scenario } & \multirow{2}{*}{$\begin{array}{c}\text { Parameter } \\
t_{1 / 2}\end{array}$} & \multirow{2}{*}{$\begin{array}{c}\text { PPL } 0 \text { mg } \\
12.7 \pm 0.602\end{array}$} & \multirow{2}{*}{$\begin{array}{c}\text { PPL } 5000 \mathrm{mg} \\
13.8 \pm 0.699\end{array}$} & \multirow{2}{*}{$\begin{array}{c}\text { Difference } \\
\text { a }(\%)\end{array}$} & \multirow{2}{*}{$\begin{array}{c}\text { PPL 15,000 } \\
\text { mg }\end{array}$} & \multirow[t]{2}{*}{$\begin{array}{c}\text { Difference } \\
\text { b (\%) }\end{array}$} \\
\hline & & & & & & & \\
\hline \multirow{2}{*}{$\begin{array}{l}\text { Single } \\
\text { dose }\end{array}$} & $40 \mathrm{mg}$ & $\begin{array}{c}C_{\max } \\
A U C_{0-t}\end{array}$ & $\begin{array}{c}12.9 \pm 0.0928 \\
294 \pm 13.8\end{array}$ & & & & \\
\hline & $60 \mathrm{mg}$ & $\begin{array}{l}C_{\max , S S} \\
A U C_{0-t}\end{array}$ & $\begin{array}{c}19.4 \pm 0.139 \\
441 \pm 20.7\end{array}$ & & & & \\
\hline \multirow{3}{*}{$\begin{array}{c}\text { Multiple } \\
\text { dose, once } \\
\text { daily }\end{array}$} & \multirow[t]{2}{*}{$40 \mathrm{mg}$} & $C_{\max , S S}$ & $18.2 \pm 0.557$ & $19.7 \pm 0.671$ & 8.35 & $\begin{array}{c}21.9 \pm \\
0.868\end{array}$ & 20.2 \\
\hline & & $A U C_{S S}$ & $294 \pm 14.0$ & $328 \pm 16.8$ & 11.6 & $376 \pm 21.5$ & 28.0 \\
\hline & $60 \mathrm{mg}$ & $\begin{array}{l}C_{\max , S S} \\
A U C_{S S}\end{array}$ & $\begin{array}{c}27.3 \pm 0.836 \\
441 \pm 21.0\end{array}$ & $\begin{array}{c}29.6 \pm 1.01 \\
492 \pm 25.2\end{array}$ & $\begin{array}{l}8.35 \\
11.6\end{array}$ & $\begin{array}{c}32.8 \pm 1.30 \\
561 \pm 32.3\end{array}$ & $\begin{array}{l}20.2 \\
28.0\end{array}$ \\
\hline \multirow{2}{*}{$\begin{array}{l}\text { Multiple } \\
\text { dose, twice } \\
\text { daily }\end{array}$} & $40 \mathrm{mg}$ & $\begin{array}{l}C_{\max , S S} \\
A U C_{S S}\end{array}$ & $\begin{array}{c}28.7 \pm 1.16 \\
294 \pm 14.0\end{array}$ & $\begin{array}{l}31.6 \pm 1.39 \\
328 \pm 16.8\end{array}$ & $\begin{array}{l}10.2 \\
11.6\end{array}$ & $\begin{array}{c}35.7 \pm 1.78 \\
376 \pm 21.5\end{array}$ & $\begin{array}{l}24.6 \\
28.0\end{array}$ \\
\hline & $60 \mathrm{mg}$ & $\begin{array}{l}C_{\max , S S} \\
A C_{S S}\end{array}$ & $\begin{array}{c}43.0 \pm 1.74 \\
441 \pm 21.0\end{array}$ & $\begin{array}{l}47.4 \pm 2.08 \\
492 \pm 25.2\end{array}$ & $\begin{array}{l}10.2 \\
11.6\end{array}$ & $\begin{array}{l}53.6 \pm 2.67 \\
564 \pm 32.3\end{array}$ & $\begin{array}{l}24.6 \\
28.0\end{array}$ \\
\hline
\end{tabular}

$C_{\max }$ and $C_{\max , S S}$, maximum concentration of DLX after the first dose and at steady state condition, respectively; $A U C_{0-t}$, area under the concentration-time curve from zero to last time after single DLX dose; $A U C_{S S}$ area under the concentration-time curve during one dosing interval at the steady state condition; the percentage difference in DLX PK parameters when drug was administered alone (PPL $0 \mathrm{mg}$ ) and (a) with PPL $5000 \mathrm{mg}$ or (b) with PPL $15,000 \mathrm{mg}$, respectively; and unit: $t_{1 / 2} \mathrm{~h} ; C_{\max }$ and $C_{\max , S S} \mathrm{ng} / \mathrm{mL}$; and $A U C_{0-t}$ and $A U C_{S S} \mathrm{~h}^{*} \mathrm{ng} / \mathrm{mL}$.

\subsection{Extrapolation of Effect of PPL on PKs of DLX in Humans}

PK profiles of DLX and 4-HD after administration of multiple DLX 40 or $60 \mathrm{mg}$ doses given once or twice daily co-administered with difference PPL doses $(0,5000$, or $15,000 \mathrm{mg} /$ day $)$ in the first day and at the steady state condition are illustrated in Figure 6. The respective PK parameters of DLX are listed in Table 4. As shown in Table 4, DLX $t_{1 / 2}$ increased by $1.1 \mathrm{~h}$ (from 12.7 to $13.8 \mathrm{~h}$ ) and $2.6 \mathrm{~h}$ (from 12.7 to $15.3 \mathrm{~h}$ ) when the drug was co-administered with PPL at doses of 5000 or 15,000 mg/day, respectively, comparing to when the drug was administered alone. Correspondingly, when DLX was administered 
once daily, the presence of PPL resulted in an increase by $11.6 \%$ and $28.0 \%$ in AUC during one dosing interval $\left(A U C_{S S}\right)$ and an increase by $8.35 \%$ and $20.2 \%$ in $C_{\max }\left(C_{\max , S S}\right)$ at the steady state. Additionally, when DLX was administered twice daily, the presence of PPL resulted in an increase by $11.6 \%$ and $28.0 \%$ in $A U C_{S S}$ and an increase by $10.2 \%$ and $24.6 \%$ in $C_{\max , S S}$ at the steady state, respectively.
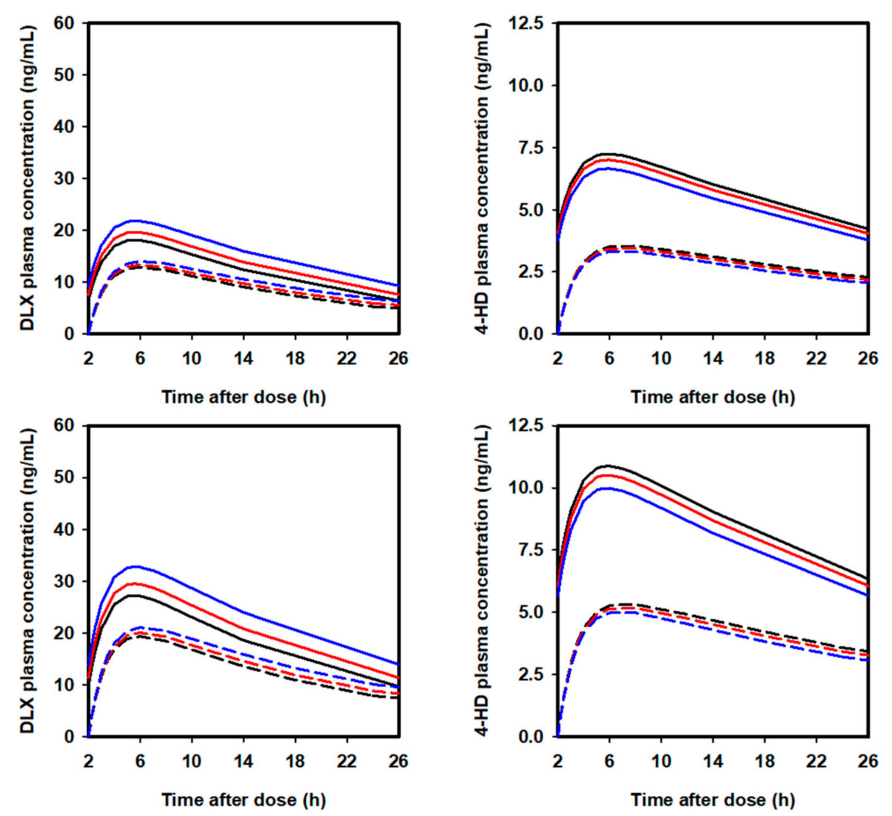

(A)
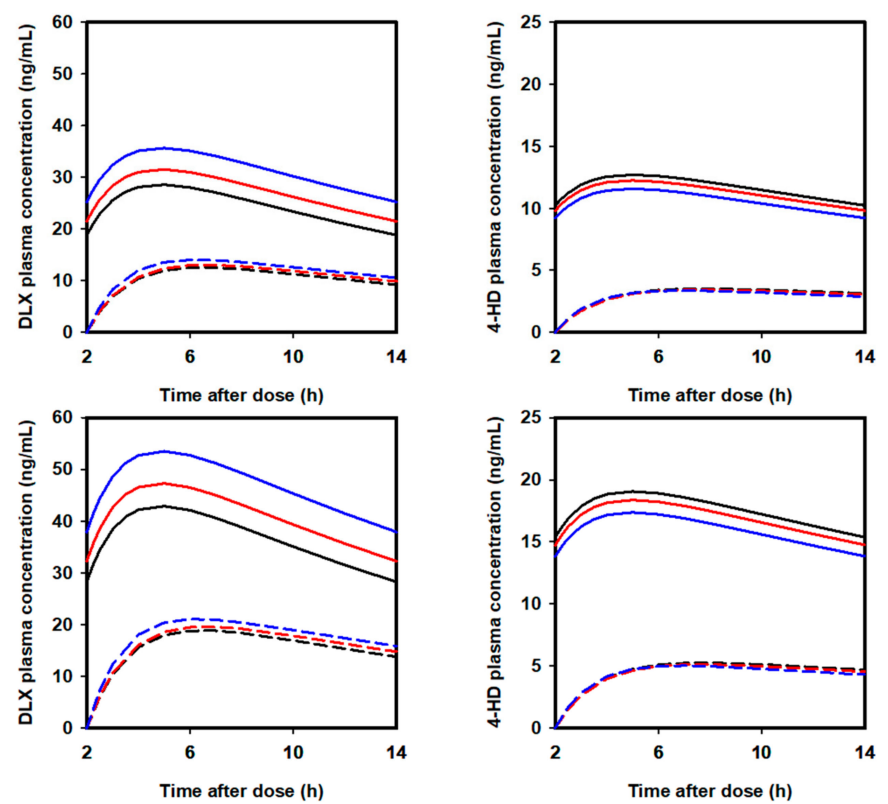

(B)

Figure 6. (A) Extrapolated concentration-time curve profiles of DLX and 4-HD at the first dosing interval (dashed line) and at the steady-state condition (solid line) following multiple DLX doses given once daily according to difference doses of PPL in humans: (black) PPL $0 \mathrm{mg}$, (red) PPL $5000 \mathrm{mg}$, and (blue) PPL 15,000 mg. (Upper) $40 \mathrm{mg}$ and (lower) $60 \mathrm{mg}$; (B) Extrapolated concentration-time curve profiles of DLX and 4-HD at the first dosing interval (dashed line) and at the steady-state condition (solid line) following multiple DLX doses given twice daily according to difference doses of PPL in humans: (black) PPL 0 mg, (red) PPL 5000 mg, and (blue) PPL 15,000 mg. (Upper) $40 \mathrm{mg}$ and (lower) $60 \mathrm{mg}$. 


\section{Discussions}

Drug interactions are one of the most common causes of medical adverse events. Therefore, evaluating potential drug interaction is an integral part of drug development. It is also important for making dosing recommendations for co-administered drugs. PK drug interactions may occur if a drug, a supplement, or food affects any one of the following four processes of another drug: absorption, distribution, metabolism, or elimination (ADME) [21,30,31].

PPL has been found to inhibit more than $50 \%$ activities of many enzymatic CYPs in a concentration-dependent manner, including CYP1A2. Changes in activity of CYP enzymes is thought to be a factor in interactions between supplements and drugs that may cause adverse events. While DLX has been reported to be a substrate of CYP450, the drug is rapidly and extensively metabolized by CYP1A2 and, to a lesser degree, metabolized by CYP2D6 to form multiple oxidative metabolites [19]. Consequently, there are probability of interactions between DLX and PPL through CYP1A2-mediated inhibition of PPL when they are co-administered in humans.

Approaches to predict human PK profiles from in vitro and/or PK profiles in preclinical species, utilizing both physiological and empirical approaches, are highly desirable [32-39], because this can drastically reduce the time and expense of drug development and dose regiment. Allometric scaling, an empirical method, has been intensively studied and widely applied to predict many important PK parameters, including $C L, V d$, and $t_{1 / 2}$, due to its simplicity [23-26]. However, allometric scaling has limitations, especially since it assumes that there are anatomical, physiological, and biochemical similarities among animals. The method may not be suitable for drugs that exhibit species-specific differences; for instance, drugs with high protein binding properties, significant biliary excretion, extensive active renal secretion, active metabolism, or show species-specific binding [40-42]. DLX is one of these cases. The drug is primarily cleared by hepatic metabolism via the activity of CYP1A2 and CYP2D6. Therefore, another method instead of a simple allometric scaling method, which can account for the difference in hepatic elimination functions between humans and rats, is required. As a result, an LBF method was selected, because it assumed that a drug clearance is proportional to the LBF of the subject; therefore, it can account for the difference in the liver functions of inter-species. By which methods, the mean apparent total clearance $\left(C L_{D L X} / F_{D L X}\right)$, volume of distribution $\left(V_{D L X} / F_{D L X}\right)$, and terminal elimination half-life $t_{1 / 2}$ of DLX in humans was estimated to be $136 \mathrm{~L} / \mathrm{h}, 2487 \mathrm{~L}$, and $12.7 \mathrm{~h}$, respectively. They are all in agreement with published literature [17-20,43-47]. For instance, according to the product information of Cymbalta (duloxetine hydrochloride) by the FDA, the volume of distribution of DLX in humans was 1640 L [17]. In the EMA product information, the apparent plasma clearance of DLX ranges from 33 to $261 \mathrm{~L} / \mathrm{h}$ (mean $101 \mathrm{~L} / \mathrm{h}$ ) after oral administration of DLX [18].

Up until now, there have been no official criteria for extrapolated data from animals to humans. However, the criteria that the prediction of PK parameters within the range of one-half and twice (also known as two-fold dimensions) of the observed data are determined to be acceptable predictions has been suggested and applied in many published studies [28,48-50]. Therefore, we also applied the two-fold dimension criteria to assess the success/failure of our predicted data. Accordingly, the present study succeeded in predicting $C L_{D L X} / F_{D L X}$ and $V_{D L X} / F_{D L X}$ parameters of DLX in humans.

The absorption rate constant of DLX in humans was predicted based on the relationship between $K_{a}, K_{e}$, and time to reach $C_{\max }\left(T_{\max }\right)$, as described in Equation (4):

$$
T_{\max }=\frac{\ln K a-\ln K e}{K a-K e}
$$

Given that DLX is acid labile, it therefore must be formulated with enteric-coated pellets to protect DLX from degradation in the acidic stomach environment by preventing DLX dissolution in the acidic stomach but allowing immediate release and rapid absorption at the small intestine. Consequently, after oral administration, there is a median 2-h lag time $\left(T_{\text {lag }}\right)$ until absorption begins [17]. Therefore, 
the $T_{\max }$ in Equation (4) was calculated as the time from when the absorption begins until the time when the $C_{\max }$ reaches, Equation (5) as follows:

$$
T_{\max }=T_{\text {max }, \text { post dose }}-T_{\text {lag }}
$$

As a result, $K_{a}$ was predicted to be $0.6971 / \mathrm{h}$, which also is in agreement with the experimental estimate in humans by Sharma et al., where Ka was around $0.61 / \mathrm{h} \mathrm{[51].}$

By applying the above-extrapolated PK parameters from rats to humans, the mean $C_{\max }$ and $A U C_{0-t}$ of DLX after a single oral administration of $60 \mathrm{mg}$ DLX were predicted to be $19.4 \mathrm{ng} / \mathrm{mL}$ and $441 \mathrm{~h}^{*} \mathrm{ng} / \mathrm{mL}$, respectively, which are reasonably similar to values reported in previous literature [20].

In conclusion, the PKs of DLX were successfully extrapolated from rats to humans by applying a method that accounted for both the pre-systemic and systemic metabolism of DLX to 4-HD. The extrapolation method developed here was further applied to investigate the potential effects of PPL, a CYP1A2 inhibitor, to the PKs of DLX when they are co-administered in humans.

Since PPL is considered to be only a health supplement, not a drug, the PPL dosage is generally recommended by manufacturers without any guidance from health organizations. PPL is designed in a capsule formulation, and one capsule contains up to $500 \mathrm{mg}$ dry extract that is equivalent to up to 5000 $\mathrm{mg}$ fresh natural PPL. The recommended dose for this product is one to three capsules daily [52-55]. The recommended dosing regimen of DLX is $60 \mathrm{mg}$ daily (given as $60 \mathrm{mg}$ once daily or $30 \mathrm{mg}$ twice daily) for major depressive disorder, diabetic peripheral neuropathic pain, and generalized anxiety disorder [17]. For stress urinary incontinence, the recommended dose is $40 \mathrm{mg}$ twice daily. Based on the response of patients to treatment, the dose may be adjusted up to $120 \mathrm{mg}$ daily (given as $60 \mathrm{mg}$ twice daily). To mimic the therapeutic dosage of DLX and PPL, we extrapolated our data at different scenarios, including DLX 40 or $60 \mathrm{mg}$ given once or twice daily and PPL $5000 \mathrm{mg} / \mathrm{day}$ (the medium dose) or 15,000 mg/day (the maximum dose). Due to a terminal elimination half-life of $12 \mathrm{~h}$, which allows steady-state conditions to be achieved after three days, PKs of DLX and 4-HD were extracted after seven days post-dose to confirm the steady-state condition.

As a result, PPL $(15,000 \mathrm{mg} /$ day) exerts a statistically significant increase in DLX exposures at steady state, with a $20.2 \%$ and $24.6 \%$ increase in DLX $C_{\max , s s}$ and the same $28.0 \%$ increase in DLX $A U C_{s s}$ when DLX was administered once or twice daily, respectively. However, a previous study has reported that despite higher DLX plasma concentrations during co-administration with fluvoxamine $\left(138 \%\right.$ increase in $C_{\max }$ and $460 \%$ increase in $\left.A U C_{0-\infty}\right)$, adverse events were not observed more often than when DLX was used alone [20]. In addition, according to the FDA and European Medicines Agency (EMA), the safety of DLX up to $120 \mathrm{mg}$ has been adequately established for the approved indications [17]. These results suggested that when DLX at the dose less than $120 \mathrm{mg}$ was administered, the increased DLX exposure due to co-administration with PPL (even at the highest PPL dose) are still within the safety range, and it may not cause clinically important safety concerns. However, at the highest DLX dose (60 mg, twice daily; equivalent to $120 \mathrm{mg} /$ day), safety issues need to be concerned, because there has been no safety test performed on doses greater than $120 \mathrm{mg} / \mathrm{day}$. In addition, due to these changes in PKs of DLX, in all cases, we suggest that the probability of interaction between DLX and PPL should to be noticed by manufacturers and health organizations.

The present study had some limitations. The inhibitory CYP1A2 effect of PPL on PKs of DLX was conducted in rats, followed by extrapolation into healthy human subjects directly. The extrapolation was conducted with the assumption that there are anatomical, physiological, and biochemical similarities among rats and humans. However, animal populations may not exactly represent human populations in these conditions. In addition, healthy subjects also may not well represent the patient populations. Therefore, to make future decisions about using a treatment combination of DLX and PPL, for instance, whether the combination should be avoided or patient safety should be monitored during co-administration in humans, future clinical studies should be conducted in diverse human populations, especially patients with liver or renal failures and patients treated with DLX. Importantly, as we mentioned above, the biological activities in PPL depend mainly upon the chemical composition of 
the constituents, which vary considerably depending on the type of plants accessible to the bees as well as the sites of collection. As the results of the drug interaction between PPL and duloxetine could be different depending on the major ingredients and its respective contents of PPL, its interpretation should be paid attention to.

\section{Material and Methods}

\subsection{Quantitative Determination of Major Ingredients in Propolis Extract}

PPL capsules were purchased from Natural Immix Health Ltd. (Port Coquitlam, BC, Canada) and Country Life Ltd. (Hauppauge, NY, USA) and pooled at the ratio 1:1 (w/w). The PPL capsules contained only PPL extract from beehives of the honey bee without additives. PPL capsules were dissolved to $200 \mu \mathrm{g} / \mathrm{mL}$ in $0.1 \mathrm{M}$ phosphate buffer ( $\mathrm{pH} 7.4$ ) containing $0.5 \%$ dimethyl sulfoxide (DMSO). Major ingredients in the PPL extract were then determined by a HPLC-MS/MS system as described in our previous report [14]. The quantities of major ingredients are shown in Table 5.

Table 5. Major ingredients and their respective contents in PPL extract.

\begin{tabular}{cc}
\hline Ingredient & $\begin{array}{c}\text { Content } \\
(\mu \mathrm{g} / \mathrm{mg})\end{array}$ \\
\hline Chrysin & $23.57 \pm 3.02$ \\
Galangin & $7.45 \pm 0.51$ \\
Kaempferide & $4.30 \pm 0.57$ \\
Kaempferol & $4.19 \pm 0.27$ \\
Caffeic acid phenethyl ester & $0.35 \pm 0.01$ \\
Apigenin & $0.19 \pm 0.10$ \\
Artepillin C & $0.05 \pm 0.04$ \\
p-Coumaric acid & $0.03 \pm 0.01$ \\
Caffeic acid & $0.01 \pm 0.00$ \\
* Each value represents the mean \pm standard deviation $(n=3$ samples $)$.
\end{tabular}

\subsection{PK Study Design in Rats and Data Analysis}

DLX and 4-HD were purchased from Waterstone Technology (Carmel, IN, USA) and Santa Cruz Biotechnology (Santa Cruz, CA, USA), respectively. Carbamazepine, used as an internal standard (IS) for analyzing DLX and 4-HD, was purchased from Sigma Chemical (St Louis, MO, USA).

The present study was approved by the Animal Ethics Committee of Chungnam National University (no. CNU-00721). It was conducted in 18 SD rats divided into 3 groups (G1, G2, and G3; $n$ $=6$ rats/group). Each was orally administered the same DLX dose $(40 \mathrm{mg} / \mathrm{kg})$ and a different PPL dose (G1, $0 \mathrm{mg} / \mathrm{kg} ; \mathrm{G} 2,500 \mathrm{mg} / \mathrm{kg}$; and G3, $1500 \mathrm{mg} / \mathrm{kg}$ ). PPL doses in the present study were the equivalent amounts of natural PPL. Blood samples $(0.3 \mathrm{~mL})$ were collected in Vacutainer ${ }^{\circledR}$ tubes (Becton Dickinson and Company, Franklin Lakes, NJ, USA) at pre-dose $(0 \mathrm{~h})$ and at various predetermined time-points $(0.25,0.5,1,2,4,8,12$, and $24 \mathrm{~h})$ post-dose. Samples were centrifuged; the plasma was then transferred to polyethylene tubes and stored at $-70{ }^{\circ} \mathrm{C}$ until analysis.

DLX and 4-HD were extracted from the plasma by a liquid-liquid extraction method, followed by analysis with a validated HPLC-MS/MS method as described in our previous report [56]. In detail, DLX and 4-HD were ionized in the positive electrospray ionization mode and detected through multiple reaction monitoring transitions at $298.00 \rightarrow 44.00$ and $314.13 \rightarrow 154.10 \mathrm{~m} / \mathrm{z}$, respectively. Calibration curves were linear over a concentration range of $5-1000 \mathrm{ng} / \mathrm{mL}$ for both these two analytes $\left(R^{2}>0.99\right)$. Separation was performed using an Atlantis C18 (50 mm $\times 4.6 \mathrm{~mm}, 3 \mathrm{~mm}$; Waters, Dublin, Ireland) column operated at $40 \pm 5^{\circ} \mathrm{C}$. The mobile phase was a mixture of methanol with $5 \mathrm{nM}$ ammonium acetate at a volume ratio of $60: 40$ and a flow rate of $0.3 \mathrm{~mL} / \mathrm{min}$. 


\subsection{Rat Population PK Model Development}

PK analysis was conducted using a software package for nonlinear mixed-effects modeling (NONMEM version 7.3.0, ICON Development Solutions, Hanover, MD, USA) [57]. The PK model was estimated using the first-order conditional estimation (FOCE) method with interaction. First, a base model was developed without characterization of the effect of PPL on the PKs of DLX. The absorption and elimination were assumed to follow first-order kinetics. The lognormal distribution was used to model the IIV in the PK parameters, as described by Equation (6).

$$
P_{i}=P_{T V} \times \exp (\eta i)
$$

where $P_{i}$ is the parameter value for the $i$ th individual, $P_{T V}$ is the typical population parameter, and $\eta_{i}$ (IIV) is the difference between $P_{i}$ and $P_{T V}$ that is assumed to be normally distributed with a mean of zero and a variance of $\omega_{\eta}{ }^{2}$. A proportional error model was applied to describe the residual random error $(\varepsilon)$ that contains contributions from IIV, assay error, and model misspecification, as expressed by Equation (7):

$$
C_{i j}=C_{\text {pred }, i j} \times\left(1+\varepsilon_{\text {pro }, i j}\right)
$$

where $C_{i j}$ and $C_{\text {pred, } i j}$ present the $j$ th observed and predicted concentrations for the $i$ th individual, respectively; $\varepsilon_{\text {pro, } i j}$ is the proportional component that has normally distributed residual random effects with a mean of zero and a variance of $\sigma^{2}$ pro.

The proposed disposition compartment model for DLX and its metabolite, 4-HD, is schematically presented in Figure 1. This model suggests two pathways of 4-HD formation from DLX: (1) pre-systemic metabolism and (2) systemic metabolism. Correspondingly, the estimated population PK parameters for 4-HD were a fraction of the metabolite converted from DLX at the depot $\left(F_{p m}\right)$, which was exerted by the first-pass liver metabolism, and the rate of the metabolite converted from DLX circulating in the plasma $\left(K_{p m}\right)$, which exerted by systemic metabolism.

The estimated population PK parameters for DLX were apparent oral clearance $\left(C L_{p m} / F_{p}\right.$ and $\left.C L_{p} / F_{p}\right)$, volume of distribution $\left(V_{p} / F_{p}\right)$, and the absorption rate constant $K_{a}$. Where $C L_{p m}$ is the clearance of DLX via conversion into 4-HD; $C L_{p}$ is the clearance of DLX via all routes except for conversion into 4-HD; $F_{p}$ is bioavailability of DLX after the first-pass effect. In other words, $F_{p}$ is the fraction of the drug that reaches the systemic circulation in relation to the amount of DLX (Amount $D L X)$ that "survives" after passing the liver from the depot. The Amount $D L X$ is calculated following the Equation (8) below:

$$
\text { Amount }_{D L X}=\text { Dose }_{D L X} \times\left(1-F_{p m}\right)
$$

Second, a covariate model to describe the possible effect of PPL on the PKs of DLX through its interaction with CYP1A2 was developed based on the base model. Covariate model building was accomplished by mixed stepwise forward addition $(p<0.05)$ and stepwise backward elimination $(p<$ 0.01) based on change in the OFV using a likelihood ratio test within NONMEM, as well as reductions in IIV of PK parameters, GOF plots, and precision of estimates. Effects of PPL on the metabolism of DLX were modeled using a Michaelis Menten equation. For example, the effects of PPL on $C L_{p m}$ is described by the Equation (9) as follows:

$$
C L_{p m}=T V C L_{p m} \times\left(1-\operatorname{Emax}_{C L p m} \times \frac{\operatorname{Dose}_{P P L}}{\operatorname{Dose}_{P P L}+I C 50_{C L p m}}\right)
$$

where $T V C L_{p m}$ is the typical value of $C L_{p m}$ in the population without co-administration with PPL, $E_{\text {max }}$ CLpm is the maximum inhibition effect of PPL on $C L_{p m}$, and $I C 50_{C L p m}$ is the co-administered dose $(\mathrm{mg} / \mathrm{kg})$ of PPL at which PPL has 50\% of the maximum inhibition effect. 


\subsection{Rat Population PK Model Evaluation}

Evaluation and selection of the models were based on graphical analysis as well as statistical methods. A nonparametric bootstrap analysis and a VPC were performed by simulating 1000 replicates each group using NONMEM. The final model assumed the same study design with same parameter estimates and their variances. Concentrations predicted from the VPC simulations were plotted against time for a $95 \% \mathrm{CI}$ of the median, $5^{\text {th }}$, and $95^{\text {th }}$ percentiles and overlaid with observed data. One thousand bootstrap replications were performed in PsN on the final model to obtain the median and $95 \%$ nonparametric $\mathrm{CI}$ (the $2.5^{\text {th }}$ and $97.5^{\text {th }}$ percentiles) for all parameters to assess parameter uncertainty.

\subsection{Extrapolating Population PK of DLX in Humans}

Assuming that an adult human has an average body weight of $70 \mathrm{~kg}, V d$ of DLX and 4-HD in humans was extrapolated from the PK parameters in rats using a simple inter-species allometric scaling method [23-26], which assumes the similarities among animals can be generalized and expressed mathematically by an allometric relationship, as presented in Equation (10):

$$
Y=a \times W^{b}
$$

where $Y$ is the parameter of interest, $W$ is the average body weight of a species, and $a$ and $b$ are the allometric coefficient and exponent of the equation, respectively. In the case of $V d$, a fixed value of 1.0 was used for the exponent in the equation [23-26]. Accordingly, the $V d$ in humans was predicted from the rat PK parameter, as presented in Equation (11):

$$
V_{\text {human }}=V_{\text {rat }} \times\left(\frac{B W_{\text {human }}}{B W_{\text {rat }}}\right)^{1.00}
$$

Clearance $(C L)$ in humans was extrapolated from rats following a method described by Ward and Smith [27], wherein $C L$ is considered to be proportional to $L B F$. Accordingly, human $C L$ was predicted following the Equation (12) below:

$$
C L_{\text {human }}=C L_{\text {rat }} \times\left(\frac{L B F_{\text {human }}}{L B F_{\text {rat }}}\right)
$$

where $L B F$ values for rats and humans are 85 and $21 \mathrm{~mL} / \mathrm{min}$ per $\mathrm{kg}$ of body weight, respectively [27].

The absorption rate constant was predicted based on an equation that describes the relationship between $K_{a}$, elimination rate constant $K_{e}$, and time to reach $C_{\max }\left(T_{\max }\right)$, as expressed by Equation (13):

$$
T_{\max }=\frac{\ln K a-\ln K e}{K a-K e}
$$

where $T_{\max }$ was extracted from literature reports for PKs of DLX in humans and $K_{\mathrm{e}}$ was calculated following the Equation (14) below:

$$
K e_{\text {human }}=\frac{C L_{\text {human }}}{V_{\text {human }}}=\frac{C L p m+C L p}{V p}
$$

To determine whether the extrapolation from rats to humans was successful or not, the extrapolated PK parameters were compared directly with the corresponding values estimated experimentally in humans. The extrapolation was assessed to be successful when the extrapolated human PK parameters lay within two-fold dimensions of the experimental values. Otherwise, it was assessed to be unsuccessful [28,48-50]. 


\subsection{Simulation of PPL Effects on PKs of DLX in Humans}

A potential effect of co-administered PPL on PKs of DLX in humans was performed by simulating 1000 replicates using the developed population PK model in rats with DLX and 4-HD. PK parameters in humans were obtained from extrapolation, as described in Section 2.4. The IIV between subjects in the human population was assumed to be the same as those in the rat population. In addition, the effects of PPL on the PKs of DLX were assumed to be constant across species.

Six scenarios for DLX and PPL co-administrations were simulated. For DLX, the drug was administered as follows: (1) 40 or $60 \mathrm{mg}$ once daily and (2) 40 or $60 \mathrm{mg}$ twice daily. For PPL, the supplement was co-administered with DLX at a total dose of (1) $0 \mathrm{mg}$, (2) $5000 \mathrm{mg}$, or (3) 15,000 mg of PPL per day. The potential effects of PPL on the PKs of DLX were assessed by comparing AUC and $C_{\max }$ of DLX with co-administration $(\mathrm{PPL}=5000$ or $15,000 \mathrm{mg}$ ) and without co-administration $(\mathrm{PPL}=0$ ) of PPL.

\section{Conclusions}

After a single oral dose of DLX $40 \mathrm{mg} / \mathrm{kg}$ in rats, PKs of DLX and its metabolite 4-HD were modeled well by a one-compartment disposition model with first-order absorption and first-order elimination. While the metabolism from DLX to 4-HD was described by both pre-systemic (first-pass effect) and systemic metabolic pathways, a Michaelis-Menten equation was used to model the CYP1A2 inhibition kinetics of PPL on the metabolism of DLX converted to 4-HD. The PK profiles of DLX, as well as the interaction of PPL with the PKs of DLX in humans, were successfully extrapolated from the corresponding PK parameters in rats by applying an allometric scaling method (for predicting volume of distribution), an LBF method (for predicting clearance), and other PK parameters in humans extracted from experimental literature, with the final developed population model in rats. In conclusion, at the DLX doses less than $120 \mathrm{mg}$, the presence of PPL exerts a statistically significant increase in DLX exposures but does not seem to exert clinically significant changes in the PKs of DLX, even at the maximum dose of PPL (15,000 mg/day). At the maximum therapeutic dose of DLX (60 mg twice daily), safety issues are required to be attended to, and the possibility of interaction between DLX and PPL might be noted. Future studies further investigating these findings should be conducted in diverse human populations to provide a better representation.

Supplementary Materials: Supplementary Materials are available online at http://www.mdpi.com/1422-0067/21/ 5/1862/s1.

Author Contributions: Conceptualization, T.L.N., C.-H.L., H.-Y.Y., W.K. and J.-W.C; Data curation, T.L.N. and C.-H.L.; Formal analysis, T.L.N., C.-H.L., H.-M.B. and S.-J.R.; Investigation, T.L.N. and K.N.; Methodology, T.L.N., C.-H.L., N.H., H.-M.B., H.-Y.Y. and J.-W.C; Supervision, W.K. and J.-W.C; Validation, T.L.N., N.H., S.-J.R. and K.N.; Writing - original draft, T.L.N.; Writing - review \& editing, T.L.N., H.-Y.Y., W.K. and J.-W.C. All authors have read and agreed to the published version of the manuscript.

Funding: This research was supported by the National Research Foundation of Korea (NRF- 2018R1C1B5085278).

Conflicts of Interest: The authors declare no conflicts of interest.

\section{References}

1. Ghisalberti, E.L. Propolis: A Review. Bee World 1979, 60, 59-84. [CrossRef]

2. Castaldo, S.; Capasso, F. Propolis, an old remedy used in modern medicine. Fitoterapia 2002, 73, S1-S6. [CrossRef]

3. Paulino, N.; Teixeira, C.; Martins, R.; Scremin, A.; Dirsch, V.; Vollmar, A.; Abreu, S.; de Castro, S.; Marcucci, M. Evaluation of the Analgesic and Anti-Inflammatory Effects of a Brazilian Green Propolis. Planta Med. 2006, 72, 899-906. [CrossRef] [PubMed]

4. El-khawaga, O.-A.Y.; Salem, T.A.; Elshal, M.F. Protective role of Egyptian propolis against tumor in mice. Clin. Chim. Acta 2003, 338, 11-16. [CrossRef]

5. Ozkul, Y.; Silici, S.; Eroğlu, E. The anticarcinogenic effect of propolis in human lymphocytes culture. Phytomedicine 2005, 12, 742-747. [CrossRef] 
6. Ahn, M.-R.; Kunimasa, K.; Kumazawa, S.; Nakayama, T.; Kaji, K.; Uto, Y.; Hori, H.; Nagasawa, H.; Ohta, T. Correlation between antiangiogenic activity and antioxidant activity of various components from propolis. Mol. Nutr. Food Res. 2009, 53, 643-651. [CrossRef] [PubMed]

7. Shehu, A.; Ismail, S.; Rohin, M.; Harun, A.; Aziz, A.; Haque, M. Antifungal Properties of Malaysian Tualang Honey and Stingless Bee Propolis against Candida Albicans and Cryptococcus Neoformans. J. Appl. Pharm. Sci. 2016, 044-050. [CrossRef]

8. Kartal, M.; Yıldız, S.; Kaya, S.; Kurucu, S.; Topçu, G. Antimicrobial activity of propolis samples from two different regions of Anatolia. J. Ethnopharmacol. 2003, 86, 69-73. [CrossRef]

9. Amoros, M.; Lurton, E.; Boustie, J.; Girre, L.; Sauvager, F.; Cormier, M. Comparison of the Anti-Herpes Simplex Virus Activities of Propolis and 3-Methyl-but-2-enyl Caffeate. J. Nat. Prod. 1994, 57, 644-647. [CrossRef]

10. Seo, K.W.; Park, M.; Song, Y.J.; Kim, S.-J.; Yoon, K.R. The protective effects of Propolis on hepatic injury and its mechanism. Phytother. Res. 2003, 17, 250-253.

11. González, R.; Corcho, I.; Remirez, D.; Rodriguez, S.; Ancheta, O.; Merino, N.; González, A.; Pascual, C. Hepatoprotective effects of propolis extract on carbon tetrachloride-induced liver injury in rats. Phyther. Res. 1995, 9, 114-117. [CrossRef]

12. Lin, S.C.; Lin, Y.H.; Chen, C.F.; Chung, C.Y.; Hsu, S.H. The hepatoprotective and therapeutic effects of propolis ethanol extract on chronic alcohol-induced liver injuries. Am. J. Chin. Med. 1997, 25, 325-332. [CrossRef] [PubMed]

13. Naramoto, K.; Kato, M.; Ichihara, K. Effects of an Ethanol Extract of Brazilian Green Propolis on Human Cytochrome P450 Enzyme Activities in Vitro. J. Agric. Food Chem. 2014, 62, 11296-11302. [CrossRef] [PubMed]

14. Ryu, C.S.; Oh, S.J.; Oh, J.M.; Lee, J.-Y.; Lee, S.Y.; Chae, J.; Kwon, K.; Kim, S.K. Inhibition of Cytochrome P450 by Propolis in Human Liver Microsomes. Toxicol. Res. 2016, 32, 207-213. [CrossRef]

15. Sasaki, T.; Sato, Y.; Kumagai, T.; Yoshinari, K.; Nagata, K. Effect of health foods on cytochrome P450-mediated drug metabolism. J. Pharm. Health Care Sci. 2017, 3, 14. [CrossRef]

16. Šarić Mustapić, D.; Debeljak, Ž.; Maleš, Ž.; Bojić, M. The Inhibitory Effect of Flavonoid Aglycones on the Metabolic Activity of CYP3A4 Enzyme. Molecules 2018, 23, 2553. [CrossRef]

17. European Medicines Agency. Cymbalta-Product Information; European Medicines Agency: Amsterdam, The Netherlands, 2004.

18. U.S. Food and Drug Administration. Cymbalta-Product Information; U.S. Food and Drug Administration: Silver Spring, MD, USA, 2004.

19. Lantz, R.J.; Gillespie, T.A.; Rash, T.J.; Kuo, F.; Skinner, M.; Kuan, H.-Y.; Knadler, M.P. Metabolism, excretion, and pharmacokinetics of duloxetine in healthy human subjects. Drug Metab. Dispos. 2003, 31, 1142-1150. [CrossRef]

20. Lobo, E.D.; Bergstrom, R.F.; Reddy, S.; Quinlan, T.; Chappell, J.; Hong, Q.; Ring, B.; Knadler, M.P. In vitro and in vivo evaluations of cytochrome P450 1A2 interactions with duloxetine. Clin. Pharmacokinet. 2008, 47, 191-202. [CrossRef]

21. U.S. Food and Drug Administration. Clinical Drug Interaction Studies—Study Design, Data Analysis, and Clinical Implications Guidance for Industry; U.S. Food and Drug Administration: Silver Spring, MD, USA, 2017.

22. European Medicines Agency Guideline on the Investigation of Drug Interactions; European Medicines Agency: Amsterdam, The Netherlands, 2012.

23. Boxenbaum, H. Interspecies scaling, allometry, physiological time, and the ground plan of pharmacokinetics. J. Pharmacokinet. Biopharm. 1982, 10, 201-227. [CrossRef]

24. Tang, H.; Hussain, A.; Leal, M.; Mayersohn, M.; Fluhler, E. Interspecies Prediction of Human Drug Clearance Based on Scaling Data from One or Two Animal Species. Drug Metab. Dispos. 2007, 35, 1886-1893. [CrossRef]

25. Caldwell, G.W.; Masucci, J.A.; Yan, Z.; Hageman, W. Allometric scaling of pharmacokinetic parameters in drug discovery: Can human CL, Vss and t1/2 be predicted fromin-vivo rat data? Eur. J. Drug Metab. Pharmacokinet. 2004, 29, 133-143. [CrossRef] [PubMed]

26. Dedrick, R.L. Animal scale-up. J. Pharmacokinet. Biopharm. 1973, 1, 435-461. [CrossRef]

27. Ward, K.W.; Smith, B.R. A comprehensive quantitative and qualitative evaluation of extrapolation of intravenous pharmacokinetic parameters from rat, dog, and monkey to humans. I. Clearance. Drug Metab. Dispos. 2004, 32, 603-611. [CrossRef] [PubMed] 
28. Nagilla, R.; Ward, K.W. A comprehensive analysis of the role of correction factors in the allometric predictivity of clearance from rat, dog, and monkey to humans. J. Pharm. Sci. 2004, 93, 2522-2534. [CrossRef] [PubMed]

29. U.S. Food and Drug Administration Bioanalytical Method Validation: Guidance for Industry. Available online: https://www.fda.gov/files/drugs/published/Bioanalytical-Method-Validation-Guidance-for-Industry. pdf (accessed on 15 June 2018).

30. Huang, S.-M.; Temple, R.; Throckmorton, D.C.; Lesko, L.J. Drug Interaction Studies: Study Design, Data Analysis, and Implications for Dosing and Labeling. Clin. Pharmacol. Ther. 2007, 81, 298-304. [CrossRef]

31. Palleria, C.; Di Paolo, A.; Giofrè, C.; Caglioti, C.; Leuzzi, G.; Siniscalchi, A.; De Sarro, G.; Gallelli, L. Pharmacokinetic drug-drug interaction and their implication in clinical management. J. Res. Med. Sci. 2013, 18, 601-610.

32. Kim, S.H.; Kim, W.B.; Lee, M.G. Interspecies pharmacokinetic scaling of a new carbapenem, DA-1131, in mice, rats, rabbits and dogs, and prediction of human pharmacokinetics. Biopharm. Drug Dispos. 1998, 19, 231-235. [CrossRef]

33. Shim, H.J.; Kim, Y.C.; Lee, J.H.; Kwon, J.W.; Kim, W.B.; Kim, Y.G.; Kim, S.H.; Lee, M.G. Interspecies pharmacokinetic scaling of DA-8159, a new erectogenic, in mice, rats, rabbits and dogs, and prediction of human pharmacokinetics. Biopharm. Drug Dispos. 2005, 26, 269-277. [CrossRef]

34. Lave, T.; Dupin, S.; Schmitt, M.; Kapps, M.; Meyer, J.; Morgenroth, B.; Chou, R.C.; Jaeck, D.; Coassolo, P. Interspecies scaling of tolcapone, a new inhibitor of catechol- $\mathrm{O}$-methyltransferase (COMT). Use of in vitro data from hepatocytes to predict metabolic clearance in animals and humans. Xenobiotica 1996, 26, 839-851. [CrossRef]

35. Mahmood, I.; Balian, J.D. Interspecies Scaling: Predicting Pharmacokinetic Parameters of Antiepileptic Drugs in Humans from Animals with Special Emphasis on Clearance. J. Pharm. Sci. 1996, 85, 411-414. [CrossRef]

36. Mahmood, I. Application of allometric principles for the prediction of pharmacokinetics in human and veterinary drug development. Adv. Drug Deliv. Rev. 2007, 59, 1177-1192. [CrossRef] [PubMed]

37. Yassen, A.; Olofsen, E.; Kan, J.; Dahan, A.; Danhof, M. Animal-to-Human Extrapolation of the Pharmacokinetic and Pharmacodynamic Properties of Buprenorphine. Clin. Pharmacokinet. 2007, 46, 433-447. [CrossRef] [PubMed]

38. Richter, W.F.; Gallati, H.; Schiller, C.D. Animal pharmacokinetics of the tumor necrosis factor receptor-immunoglobulin fusion protein lenercept and their extrapolation to humans. Drug Metab. Dispos. 1999, 27, 21-25. [PubMed]

39. Ward, K.W.; Coon, D.J.; Magiera, D.; Bhadresa, S.; Struharik, M.; Lawrence, M.S. Exploration of the African green monkey as a preclinical pharmacokinetic model: Oral pharmacokinetic parameters and drug-drug interactions. Xenobiotica 2009, 39, 266-272. [CrossRef]

40. Mahmood, I. Integration of in Vitro Data and Brain Weight in Allometric Scaling to Predict Clearance in Humans: Some Suggestions. J. Pharm. Sci. 1998, 87, 527-529. [CrossRef]

41. Lavé, T.; Coassolo, P.; Reigner, B. Prediction of hepatic metabolic clearance based on interspecies allometric scaling techniques and in vitro-in vivo correlations. Clin. Pharmacokinet. 1999, 36, 211-231.

42. Huang, Q.; Riviere, J.E. The application of allometric scaling principles to predict pharmacokinetic parameters across species. Expert Opin. Drug Metab. Toxicol. 2014, 10, 1241-1253. [CrossRef]

43. Tianmei, S.; Knadler, M.P.; Lim, M.T.; Yeo, K.P.; Teng, L.; Liang, S.; Pan, A.X.; Lobo, E.D. Pharmacokinetics and tolerability of duloxetine following oral administration to healthy Chinese subjects. Clin. Pharmacokinet. 2007, 46, 767-775. [CrossRef]

44. Lobo, E.D.; Loghin, C.; Knadler, M.P.; Quinlan, T.; Zhang, L.; Chappell, J.; Lucas, R.; Bergstrom, R.F. Pharmacokinetics of duloxetine in breast milk and plasma of healthy postpartum women. Clin. Pharmacokinet. 2008, 47, 103-109. [CrossRef]

45. Skinner, M. Duloxetine is both an inhibitor and a substrate of cytochrome P4502D6 in healthy volunteers. Clin. Pharmacol. Ther. 2003, 73, 170-177. [CrossRef]

46. Li, H.; Li, T.; Li, Y.; Shen, Y. Pharmacokinetics and Safety of Duloxetine Enteric-coated Tablets in Chinese Healthy Volunteers: A Randomized, Open-label, Single- and Multiple-dose Study. Clin. Psychopharmacol. Neurosci. 2013, 11, 28-33. [CrossRef] [PubMed]

47. Chan, C.; Yeo, K.P.; Pan, A.X.; Lim, M.; Knadler, M.P.; Small, D.S. Duloxetine pharmacokinetics are similar in Japanese and Caucasian subjects. Br. J. Clin. Pharmacol. 2007, 63, 310-314. [CrossRef] [PubMed] 
48. Jolivette, L.J.; Ward, K.W. Extrapolation of human pharmacokinetic parameters from rat, dog, and monkey data: Molecular properties associated with extrapolative success or failure. J. Pharm. Sci. 2005, 94, 1467-1483. [CrossRef] [PubMed]

49. Evans, C.A.; Jolivette, L.J.; Nagilla, R.; Ward, K.W. Extrapolation of preclinical pharmacokinetics and molecular feature analysis of "discovery-like" molecules to predict human pharmacokinetics. Drug Metab. Dispos. 2006, 34, 1255-1265. [CrossRef] [PubMed]

50. Feng, M.R.; Lou, X.; Brown, R.R.; Hutchaleelaha, A. Allometric pharmacokinetic scaling: Towards the prediction of human oral pharmacokinetics. Pharm. Res. 2000, 17, 410-418. [CrossRef]

51. Sharma, A.; Goldberg, M.J.; Cerimele, B.J. Pharmacokinetics and safety of duloxetine, a dual-serotonin and norepinephrine reuptake inhibitor. J. Clin. Pharmacol. 2000, 40, 161-167. [CrossRef]

52. Ferngrove Pharmaceuticals Australia Pty Ltd. Black Propolis $5000 \mathrm{mg}$. Available online: https://global. rakuten.com/en/store/the-natural/item/plo5000-100c/ (accessed on 14 April 2019).

53. Ever Health EverHealth Propolis 5000, 120 Capsules. Available online: http://www.everhealth.co.nz/portfolioitem/propolis5000/ (accessed on 14 April 2019).

54. My Natural Health Limited Health Vibrant Propolis 5000. Available online: https://www.mynaturalhealth. co.nz/products/view/health-vibrant-propolis-5000 (accessed on 25 February 2019).

55. True Blue Premium Dark Bee Propolis 5000mg 250 Capsules Australian Made. Available online: https://www. amazon.com/True-Blue-Propolis-Capsules-Australian/dp/B0768SLYK8 (accessed on 15 February 2019).

56. Chae, J.; Baek, H.; Kim, S.K.; Kang, H.; Kwon, K. Quantitative determination of duloxetine and its metabolite in rat plasma by HPLC-MS/MS. Biomed. Chromatogr. 2013, 27, 953-955. [CrossRef]

57. Boeckmann, A.J.; Beal, S.L.; Sheiner, L.B. NONMEM User's Guide, Part I; NONMEM Project Group, University of California at San Francisco: San Francisco, CA, USA, 1998.

(C) 2020 by the authors. Licensee MDPI, Basel, Switzerland. This article is an open access article distributed under the terms and conditions of the Creative Commons Attribution (CC BY) license (http://creativecommons.org/licenses/by/4.0/). 